\title{
Mining
}

http://dx.doi.org/10.1590/0370-44672018720080

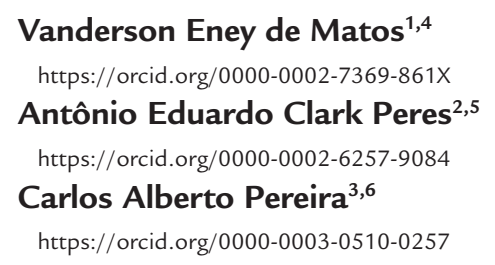

Stephânia da Consolação Silva Nogueira ${ }^{1,7}$

https://orcid.org/0000-0002-5801-8241

${ }^{1}$ Universidade Federal de Minas Gerais - UFMG,

Escola de Engenharia - PPGEM,

Belo Horizonte - Minas Gerais - Brasil.

${ }^{2}$ Universidade Federal de Minas Gerais - UFMG, Escola de Engenharia, Departamento de Engenharia Metalúrgica e de Materiais, Belo Horizonte - Minas Gerais - Brasil.

${ }^{3}$ Universidade Federal de Ouro Preto - UFOP, Escola de Minas, Departamento de Engenharia de Minas, Ouro Preto - Minas Gerais - Brasil.

E-mails: ${ }^{4}$ vandersoneney7@gmail.com, 5aecperes@demet.ufmg.br, ${ }^{6}$ pereira@demin.ufop.br, pereiraufop@gmail.com, ${ }^{7}$ ninhanogueira@yahoo.com.br

\section{Analysis of quartz floatability using design of experiments}

\section{Abstract}

Quartz floatability in cationic reverse flotation depends on the suitable choice of surfactant type and the conditions under which they are applied. The design of experiments (DOE) allows the evaluation of process variables, in a structured and independent way, with statistical validation and a limited number of tests. Tests of microflotation of quartz, in the size range $-150+75 \mu \mathrm{m}$, using factorial design of experiments, showed that etherdiamine leads to higher level of quartz floatability than ethermonoamine, favored by increase in collector concentration, at the high level of $\mathrm{pH}$ tested (11.0). Floatability values above $90 \%$ were achieved with the use of $3 \mathrm{mg} / \mathrm{L}$ of ether diamine for both $\mathrm{pH}$ levels, while with ether monoamine the target was reached only at $\mathrm{pH} 11$.

keywords: floatability of quartz, ethermonoamine, etherdiamine, microflotation.

\section{Introduction}

The major routes used in iron ore concentration are froth flotation and magnetic separation. Low intensity magnetic separation was intensively applied to concentrate magnetic taconites in the USA. Froth flotation was then introduced for concentration of non magnetic taconites. In Brazil, the production of iron ore concentrates from itabirites started in 1972 with the use of WHIMS (wet high intensity magnetic separation). The decrease of iron grade in the ROM (run of mine) ore, the more complex associations of iron oxides with gangue minerals, and the more strict specifications of the iron and steel making industry induced a gradual replacement of WHIMS by flotation or a combination of both techniques (Silva et al., 2017).

The flotation routes viable for use in iron ore concentration are direct flotation of iron oxides and reverse quartz flotation, either via the anionic route after surface activation or the cationic one (Araujo et al., 2005; Filippov et al., 2014). The reverse cationic flotation of quartz is the most widely utilized in the beneficiation of low grade iron ores, such as the Brazilian itabirites, for the production of high quality pellet feed (Araujo et al., 2005; Vieira and Peres, 2007; Filippov et al., 2014). The anionic flotation is widely applied to low grade Chinese ores.

Froth flotation is a concentration process in which the differential property is induced by the adsorption of reagents onto the surface of mineral particles and other interfaces present in the system. Reagents control the hydrophobicity of the mineral particles rendering possible the selective separation.

The collectors currently used are ether amines partially neutralized with acetic acid (forming etheramine acetate), divided in two classes: ethermonoamines 
$\left(\mathrm{R}-\mathrm{O}\left(\mathrm{CH}_{2}\right)_{3} \mathrm{NH}_{2}\right)$ and etherdiamines $\left(\mathrm{R}-\mathrm{O}\left(\mathrm{CH}_{2}\right)_{3} \mathrm{NH}\left(\mathrm{CH}_{2}\right)_{3} \mathrm{NH}_{2}\right)$. In aqueous medium, at alkaline $\mathrm{pH}$, these cationic surfactants dissociate via protonation in ionic and molecular species, also being able to play the role of frother (Bulatovic, 2007). The equilibrium between ionic and molecular species concentrations is a $\mathrm{pH}$ value defined as pKA (Ari, 2001; Mhonde, 2016).

Matos (2017) investigated the performance of ethermonoamine and etherdiamine in the bench scale flotation of a low grade iron ore in two size ranges: coarse $(\mathrm{d} 50=70 \mu \mathrm{m})$ and fine $(\mathrm{d} 50=20 \mu \mathrm{m})$. For both size ranges lower $\mathrm{SiO}_{2}$ grade in the concentrate was achieved with ethermonoamine, while etherdiamine yielded a higher iron metallurgical recovery. Vieira and Peres (2007) conducted column flotation tests using pure quartz in three size ranges (coarse $-297+150 \mu \mathrm{m}$; medium $-150+74 \mu \mathrm{m}$; fine $-74+38 \mu \mathrm{m}$ ) and ethermonoamine and etherdiamine as collectors. Etherdiamine was more effective in the flotation of medium and coarse particles, while a

\section{Materials and methods}

The quartz samples were hand collected in the Iron Quadrangle, Minas Gerais state, Brazil, comminuted and screened in laboratory sieves. The fraction in the size range between $75 \mu \mathrm{m}$ and $150 \mu \mathrm{m}$ was washed in tap water, without addition of any chemicals and purified with a hand magnet. The results of the quantitative chemical analysis were: 98.90\% $\mathrm{SiO}_{2} ; 0.81 \% \mathrm{Fe}_{2} \mathrm{O}_{3} ; 0.14 \% \mathrm{Al}_{2} \mathrm{O}_{3}$.

The evaluated collectors were ethermonoamine PA14F-30 and etherdiamine better performance of ethermonoamine was observed in the case of fine particles. Araujo et al. (2005) reported that "blending di-amines and mono-amines is usual practice in a large concentrator to achieve low silica contents in the concentrate".

Reverse cationic flotation of itabirite iron ores is considered a well established plant practice in operation since 1978 . Nevertheless the number of chemical, physical, and physicochemical variables is large and neither the individual effect of most of them nor the effects of their interactions are well known.

The following variables, among other, are relevant for the understanding of the complex reverse cationic flotation of iron ores (Nagaraj, 2005; Filippov et al., 2014; Matos, 2017):

i. collector: ethermonoamine, etherdiamine, modified etheramine, ether amines blends, dosage, chain length;

ii. depressant: source of starch (corn, cassava, sorghum, other), degree of purity, composition (amylopectin:amylose ratio), carboxymethylcellulose, guar gum, synthetic polymer;

M73, supplied by Air Products, as acetates (neutralization degree $\mathrm{ND}=30 \%$ ). The solutions were diluted to $0.5 \% \mathrm{w} / \mathrm{v}$ with distilled water. A $1 \%(\mathrm{w} / \mathrm{v}) \mathrm{NaOH}$ solution, also diluted with distilled water, was used for $\mathrm{pH}$ control.

The microflotation tests were conducted in a modified Hallimond tube apparatus illustrated in Figure 1. Both fractions (floated and unfloated) were dried, filtered, and weighed in analytical balance model AUW220D/

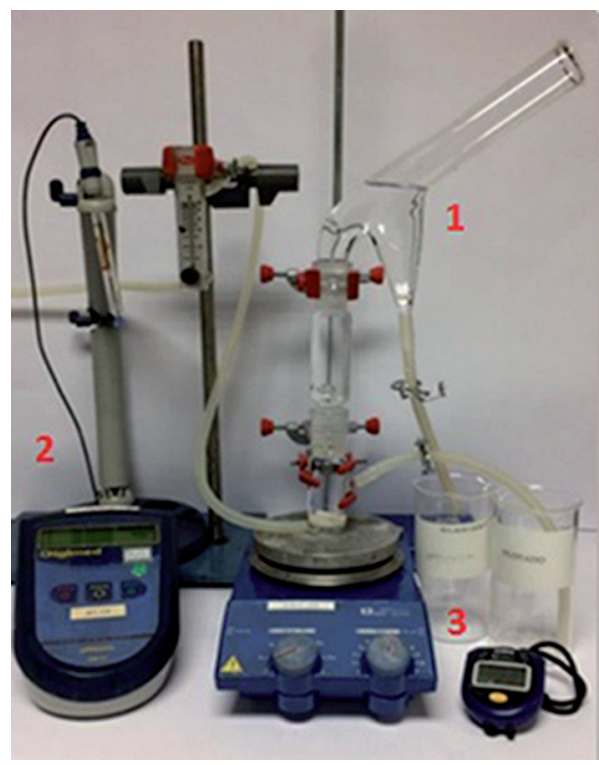

iii. use of tailored frothers for specific action;

iv. $\mathrm{pH}$ : action on the dispersion degree, $\mathrm{pKa}$ of the collector;

v. mineralogical composition of the ore;

vi. particles size range in the pulp.

The design of experiments provides the conduction of tests in a structured way. The variation of independent variables are under control, providing the evaluation of their influence on the response variable with a small number of tests.

Successful application of the technique was reported by Feng and Aldrich (2004), who evaluated the influence of operation parameters, such as pulp temperature, collector dosage, pulp $\mathrm{pH}$, and grinding condition (dry or wet) on the flotation of apatite via multilinear regression.

This investigation aims to provide preliminary information on this complex universe of effects addressing the variables amine type, amine concentration, and $\mathrm{pH}$ and their interactions on the floatability of quartz.

SHIMADZU (d=0.1 mg/0.01 mg) for determination of floatability. The tests were designed according to a DOE $2^{3}$ (Table 1), in which the defined variables and levels were collector type (ethermonoamine and etherdiamine), collector concentration (1 and $3 \mathrm{mg} / \mathrm{L}$ ), and flotation $\mathrm{pH}$ (10 and 11). Quartz floatability was defined as variable response. The tests followed random sequence and the statistical analysis of data used the software Minitab 17.

Figure 1

Experimental apparatus

of microflotation tests: 1 - modified Hallimond tube supplied by Hialoquímica, 2 - pHmeter Digimed, 3 - timer Technos. 
Table 1

Design of experiments.

\begin{tabular}{c|c|c|c|c} 
Stand Order & Seq Order & Collector Type & Collector Concentration & $\mathbf{p H}$ \\
\hline 4 & T01 & Etherdiamine & $3 \mathrm{mg} / \mathrm{L}$ & 10 \\
\hline 8 & T02 & Etherdiamine & $3 \mathrm{mg} / \mathrm{L}$ & 11 \\
\hline 1 & T03 & Ethermonoamine & $1 \mathrm{mg} / \mathrm{L}$ & 10 \\
\hline 7 & T04 & Ethermonoamine & $3 \mathrm{mg} / \mathrm{L}$ & 11 \\
\hline 2 & T05 & Etherdiamine & $1 \mathrm{mg} / \mathrm{L}$ & 10 \\
\hline 3 & T06 & Ethermonoamine & $3 \mathrm{mg} / \mathrm{L}$ & 10 \\
\hline 5 & T07 & Ethermonoamine & $1 \mathrm{mg} / \mathrm{L}$ & 11 \\
\hline 6 & T08 & Etherdiamine & $1 \mathrm{mg} / \mathrm{L}$ & 11 \\
\hline
\end{tabular}

\section{Results and discussion}

The results of all tests, with respect to the variable collector type, amine con-

Table 2

Data and results of tests.

centration, and $\mathrm{pH}$ are shown in Table 2, cube plot in Figure 2.

and can be visualized in the vertices of the

\begin{tabular}{c|c|c|c|c} 
Seq Order & Initial mass $(\mathrm{g})$ & Floated mass $(\mathrm{g})$ & Bulk mass $(\mathrm{g})$ & Quartz Floatability \\
\hline T01 & 1.00489 & 0.92539 & 0.07087 & $92.89 \%$ \\
\hline T02 & 1.00159 & 0.93613 & 0.06406 & $93.60 \%$ \\
\hline T03 & 1.00404 & 0.42112 & 0.57230 & $42.39 \%$ \\
\hline T04 & 1.00368 & 0.90987 & 0.08292 & $91.65 \%$ \\
\hline T05 & 1.00602 & 0.75681 & 0.24604 & $75.47 \%$ \\
\hline T06 & 1.00357 & 0.86197 & 0.13613 & $86.36 \%$ \\
\hline T07 & 1.00597 & 0.56995 & 0.45261 & $55.74 \%$ \\
\hline T08 & 1.00132 & 0.82856 & 0.16380 & $83.49 \%$ \\
\hline
\end{tabular}

Cub Plot (adjusted means) for Flotability

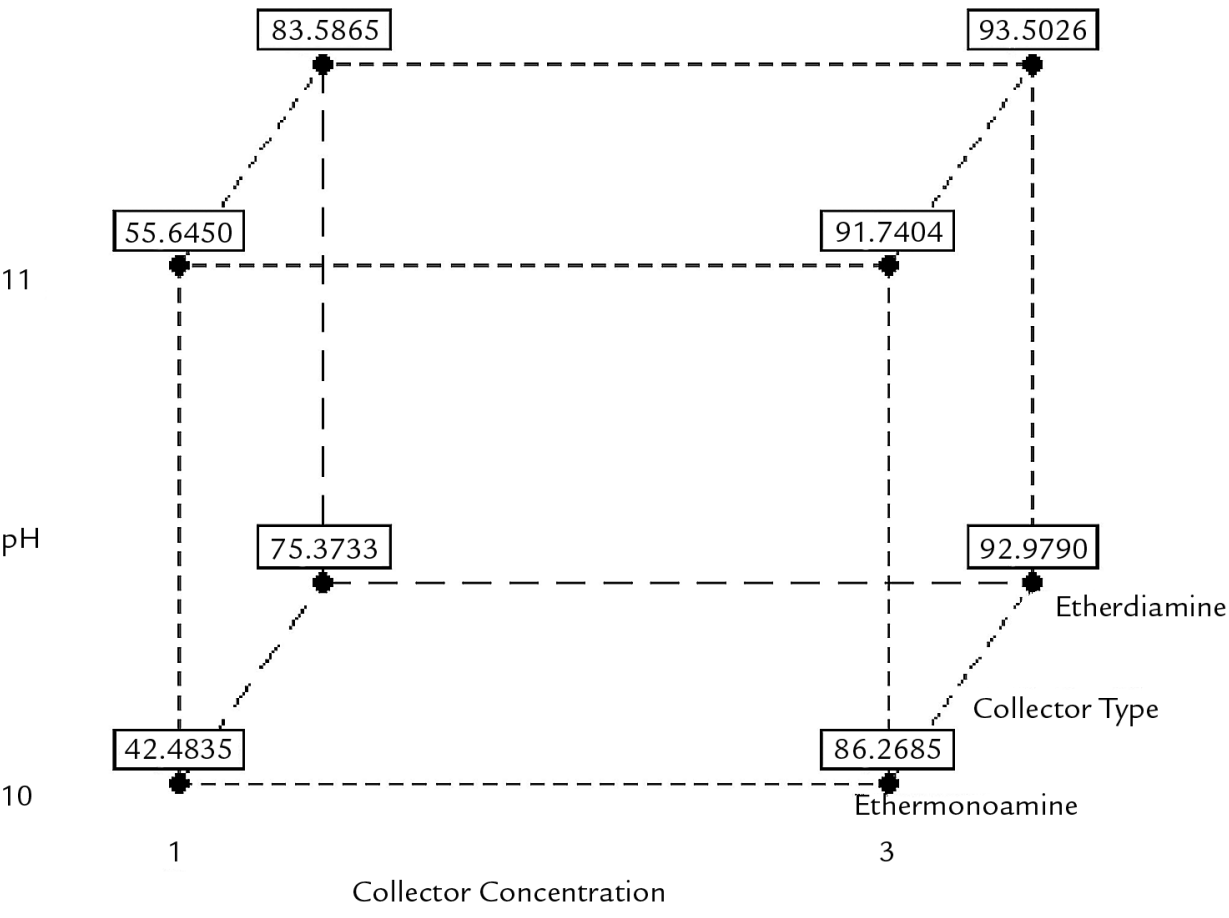

Cube plot of the adjusted means for floatability.

The results shown on the Pareto plot indicate that all tested variables and their interactions are statistically significant for the response, considering a $95 \%$ confidence interval. This analysis is based

on the absolute value of the effects (reference line $=12.7$ ) for factorial experiments without replicates, defined by the Pseudo Standard Error (PSE) of the Lenth method. All variables and their interactions present standard effects above this value, as can be observed in the Figure 3. The sequence of significance is: collector concentration, collector type, interaction collector concentration /collector type, and $\mathrm{pH}$. 


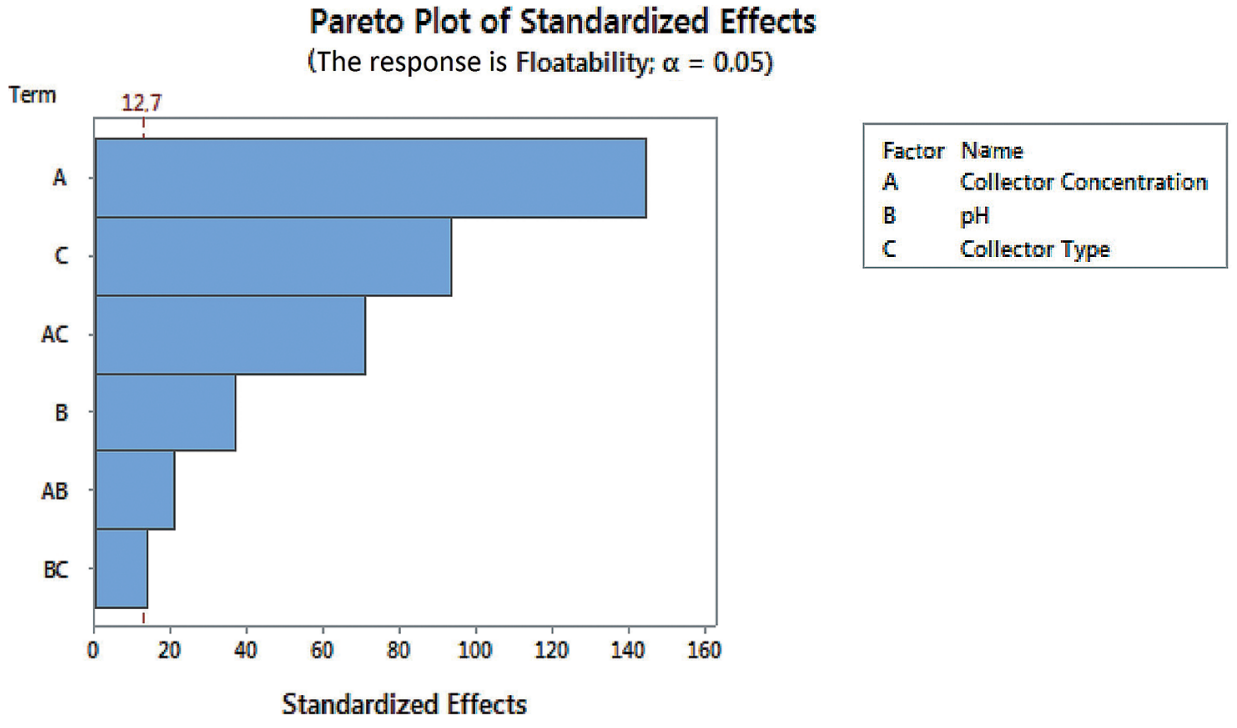

The DOE method allows the modelling of quartz floatability $(\mathrm{QF})$ as a linear regression function (Equation 1) of tested variables collector type (CT),
Figure 3

Pareto plot of the standardized effects.

collector concentration (CC), $\mathrm{pH}$ and their interactions.

$$
Q F=C+\alpha_{1} C T+\alpha_{2} C C+\alpha_{3} p H-\beta_{1}\left(C T^{*} C C\right)-\beta_{2}\left(C T^{*} p H\right)-\beta_{3}\left(C C^{*} p H\right)
$$

where, C - constant; $\alpha_{1}, \alpha_{2}$, and $\alpha_{3}$ - linear coefficient of variables; $\beta_{1}, \beta_{2}$, and $\beta_{3}$ - linear coefficient of interacting variables.
Equation (2) presents the linear regression equation for the floatability with respect to coefficient values for the tested variables and their first order interactions, with a regression order of $99.98 \%$. For the calculation of floatability, (-1) is used for ethermonoamine and (1) for etherdiamine.

$$
\begin{gathered}
\text { Floatability }=-101.74+47.73 * \mathrm{CT}+53.80^{*} \mathrm{CC}+14.532 * \mathrm{pH}-6.5448^{*} \mathrm{CT}{ }^{*} \mathrm{CC}-2.474 *{ }^{*} \mathrm{CT}{ }^{*} \mathrm{pH}-3.845^{*} \mathrm{CC}^{*} \mathrm{pH} \\
\mathrm{R}^{2}=99.98 \%
\end{gathered}
$$

The analysis of the main effects, considering adjusted means, shows that etherdiamine leads to higher floatability levels in comparison with ethermonoamine and that the floatability increases with the high amine concentration and for the high $\mathrm{pH}$ levels, as observed on Figure 4. This effect is explained by the higher adsorption density of etherdiamine on the quartz surface, due to the presence of the additional NH cationic group and extra pair of electrons with respect to ether monoamine. There are differences in the dissociation of the collectors, but there are no reliable references in literature for the pKa of the reagents utilized (Ari, 2001; Mhonde, 2016).

The results are similar to those achieved by Vieira and Peres (2007) for the same size range, but the comparison is not possible due to the fact that equipment, reagents, and concentrations were not the same. Ma et al. (2009) investigated the floatability of kaolinite $\left(\mathrm{Al}_{2} \mathrm{Si}_{2} \mathrm{O}_{5}(\mathrm{OH})_{4}\right)$, silicate that is present in iron ores, reaching the conclusion that ether monoamine in the acidic $\mathrm{pH}$ ranges and high concentrations yields high floatability in opposition to the low or nihil floatability with ether diamine.

\section{Plot of Main Effects for Floatability} Adjusted Mean

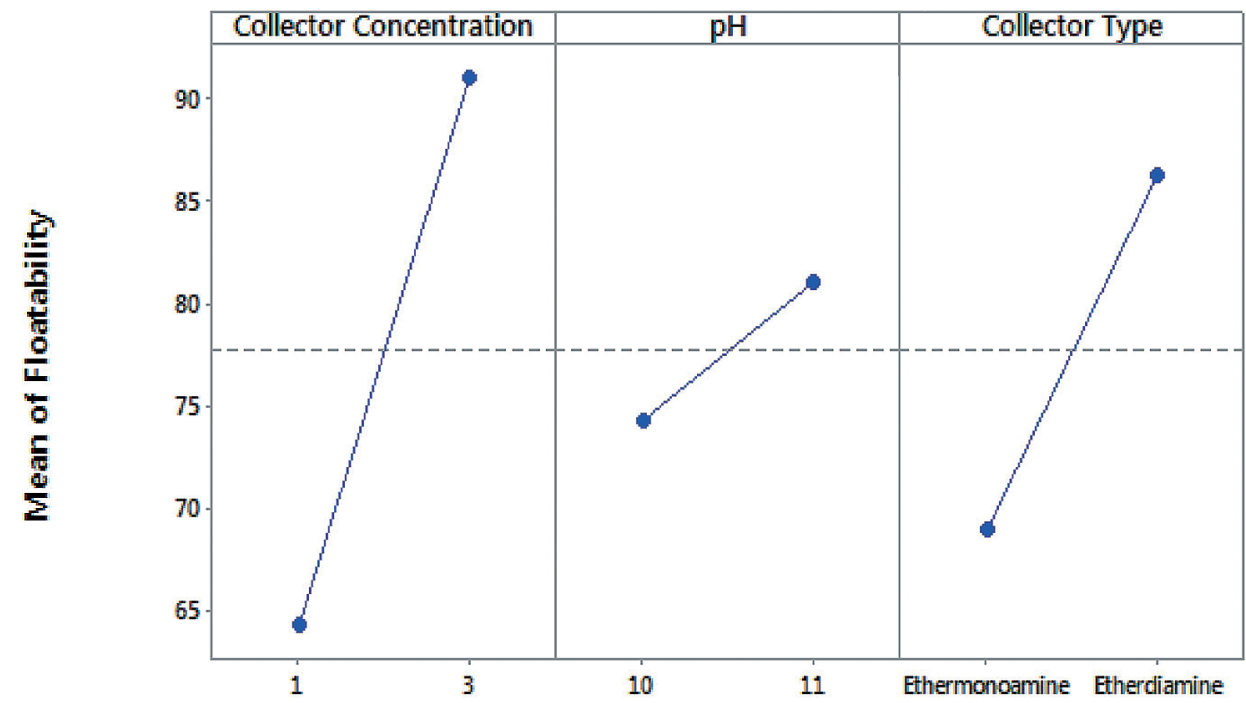

Figure 4

Plot of main effects of the adjusted means for floatability. 
Plots of interactions among the variables are presented in Figure 5, where stratified plots as function of collector concentration and $\mathrm{pH}$ clearly show that etherdiamine was more effective than ethermonoamine.

Figure 5

Plot of the adjusted means interaction for floatability.

Figure 6 Plot of superimposed contours of floatability against amine concentration and $\mathrm{pH}$ : a) - Ethermonoamine; b) - Etherdiamine.
The DOE allows the building of over imposed contour plots, providing the identification of areas where a certain level of floatability may be achieved as a function of the tested variables. In Figure 6, one may observe regions where floatability levels above $90 \%$ may be achieved with the use of ethermonoamine (white area in Figure 6a) and use of etherdiamine (larger white area in Figure 6b).

Interaction Plot for Floatability

Adjusted Mean

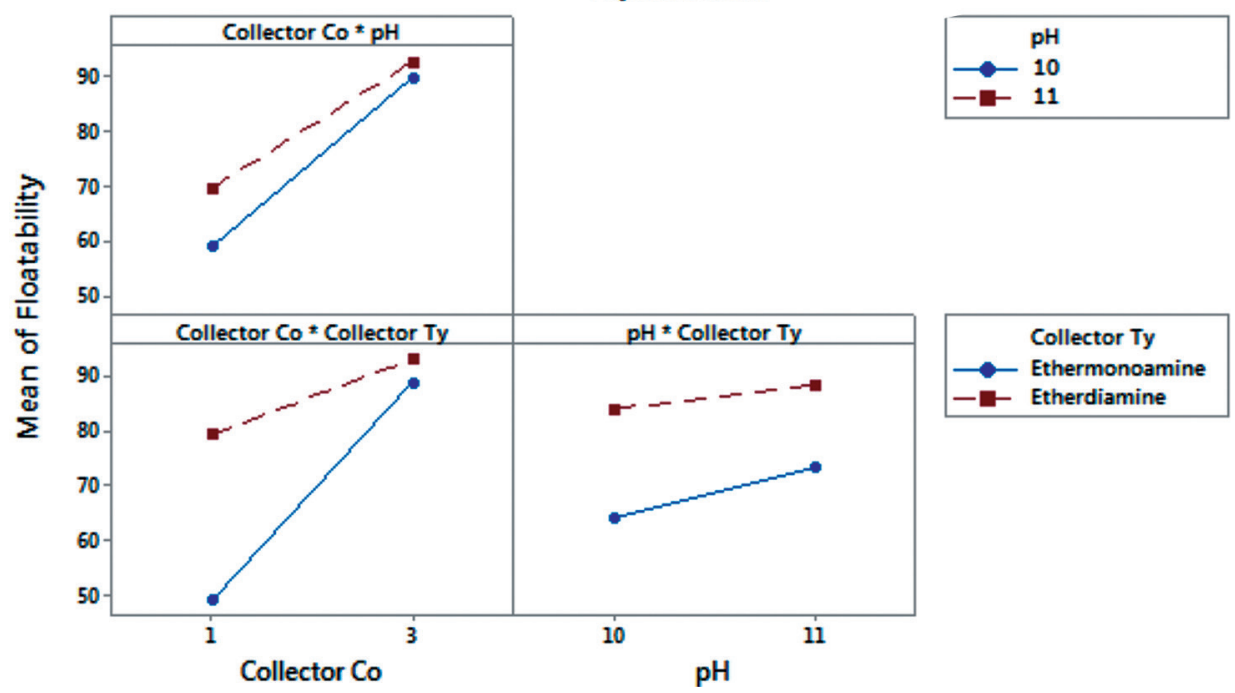

Contour plot of Floatability

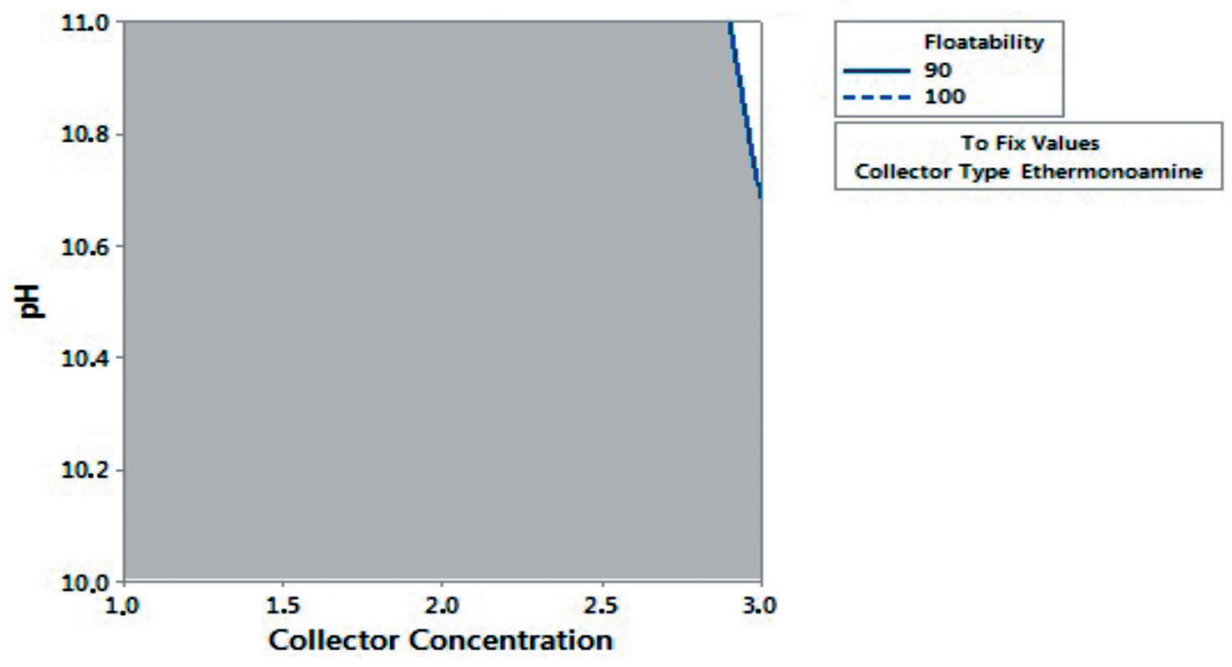

(b)

Contours Plot of Floatability
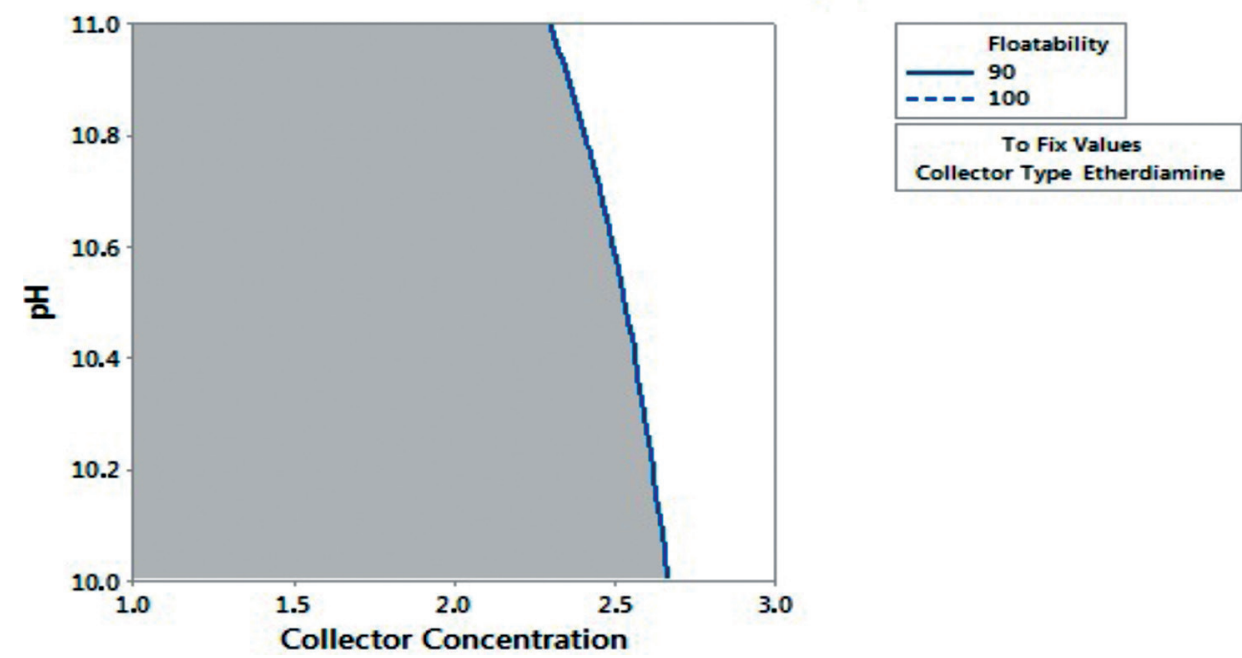
The use of the DOE methodology has proved to be efficient to evaluate multivari-

\section{Conclusions}

The floatability of quartz is significantly affected by the variable amine concentration (1 and $3 \mathrm{mg} / \mathrm{L})$, collector able issues, providing a lot of structured information from a small number of tests.

$$
\mathrm{QF}=\mathrm{C}+\alpha_{1} \mathrm{CT}+\alpha_{2} \mathrm{CC}+\alpha_{3} \mathrm{pH}-\beta_{1}\left(\mathrm{CT}^{*} \mathrm{CC}\right)-\beta_{2}\left(C T^{*} \mathrm{pH}\right)-\beta_{3}\left(C \mathrm{C}^{*} \mathrm{pH}\right)
$$

Quartz achieves higher floatability levels with etherdiamine than with ether monoamine, due to structural differences between the reagents. The floatability

\section{Acknowledgements}

This study was financed in part by the Coordenação de Aperfeiçoamento de Pessoal de Nível Superior - Brasil (CAPES)

\section{References}

type (ethermonoamine and etherdiamine), $\mathrm{pH}$ (10 and 11) and their primary interactions. This response may be modeled by the linear regression:

concentration $3 \mathrm{mg} / \mathrm{L}$ for both $\mathrm{pH}$ values. This target was achieved by ethermonoamine for the concentration $3 \mathrm{mg} / \mathrm{L}$ and $\mathrm{pH} 11$.

to PPGEM and Laboratory of Flotation (DEMIN/UFOP) for the support on conduction of experiments.
The authors also acknowledge CNPq, FAPEMIG, CAPES for the support
ARAUJO, A. C., VIANA, P. R. M., PERES, A. E. C. Reagents in iron ores flotation. Minerals Engineering, v. 18, p. 219-224, 2005.

ARI, V. Flotation of silicated minerals: physico-chemical studies in the presence of alkylamines and mixed (cationic/anionic/non-ionic) collectors. Lulea: Engineering School of Lulea University of Technology, 2001. 59p. (Doctoral Thesis).

BULATOVIC, S. M. Handbook of flotation reagents. Amsterdam: Elsevier Science \& Technology Books, 2007. 446 p.

FENG, D., ALDRICH, C. Influence of operating parameters on the flotation of apatite. Minerals Engineering, v. 17, n. 3, p. 453-455, 2004.

FILIPPOV, L.O., SEVEROV, V. V., FILIPPOVA, I. V. An overview of the beneficiation of iron ores via reverse cationic flotation. Minerals Engineering, v. 127, n. 2, p. 62-69, 2014

MA, X., BRUCKARD, W. J., HOLMES, R. Effect of collector, pH and ionic strength on the cationic of kaolinite. Minerals Engineering, v. 93, p. 54-58, 2009.

MATOS, V. E. Seletividade de reagentes na flotação reversa de minério de ferro. Belo Horizonte: Escola de Engenharia da Universidade Federal de Minas Gerais, 2017. 116p. (M.Sc. Thesis in Portuguese).

MHONDE, N. P. Investigating collector and depressant performance in the flotation of selected iron ores. Cape Town: University of Cape Town, 2016. 145p. (M.Sc Thesis).

NAGARAJ, R. D. Reagent selection and optimization - the case for a holistic approach. Minerals Engineering, v. 18, p.151-158, 2005.

SILVA, J. P. M., PERES, A. E, C., ISAAC, A. C. Process route for low grade itabirites concentration: magnetic separation preceding flotation. Mineral Processing and Extrative Metallurgy Review, v. 39, n. 1, p. 68-72, 2017.

VIEIRA, A. M., PERES, A. E. C. The effect of amine type, $\mathrm{pH}$, and size range in the flotation of quartz. Minerals Engineering, v. 20, p. 1008-1013, 2007.

Received: 23 August 2018 - Accepted: 30 January 2019. 